\title{
Determination of correction factor of self-absorption for lead- 210 in environment samples using spike method
}

\author{
Jawaher Al-Tuweity ${ }^{1, *}$, Hassan Kamleh ${ }^{2}$, M. Said Al-Masri ${ }^{3}$, A.Wael Doubal ${ }^{4}$, Azougagh Mohamed ${ }^{5}$, El Mehdi \\ Alibrahmi ${ }^{1}$, Hamid Boukhal $^{6}$, and El Mahjoub Chakir $^{1}$ \\ ${ }^{1}$ LPMS, Physics Department, University of Ibn Tofail UIT, P. O. Box 133, Kenitra, Morocco \\ ${ }^{2}$ Physics Department, Damascus University, Damascus, Syria \\ ${ }^{3}$ Department of Protection and Safety, Atomic Energy Commission of Syria AECS, Damascus, Syria \\ ${ }^{4}$ Basic Science Department, Faculty of Electrical and Mechanical Engineering, Damascus University, Syria \\ ${ }^{5}$ ENSAM Rabat université MohammedV - Rabat-Morocco \\ ${ }^{6}$ Université Abdelmalek Saadi - Faculté des Sciences- Tétouan - Morocco
}

\begin{abstract}
In environment radiation measurement, calculation the correction factors are critical, especially for low energy measurement because of self-absorption phenomena. In this work the main purpose is to determination the self-absorption correction factors of lead-210 (210Pb) energy $(46.5 \mathrm{keV})$ in various environment samples (7 sediments, 5 soil) using an experimental method called Spike Method. The samples were collecting from different places in Syrian. They were prepared according to the laboratory producers starting from collecting, cleaning, drying, grounding, hemogenic and calculating the appearance density. Low-energy gamma spectroscopy HPGe was used for radiation analysis which available at the laboratories of the Protection and Safety Department - Syrian Atomic Energy Commission - Syria. The spike method depends on adding a quantity of a standard solution with a known activity which contains lead isotope $210 \mathrm{~Pb}$ and added to the studied samples. Self-absorption correction factors (CF) calculated by the ratio of the count rate or activity of spiked and unspiked samples. The CF for sediment samples were between $29 \%$ to $54 \%$ and for soil samples, the CFs were between $38 \%$ to $56 \%$ recording correction higher than sediment samples. The results showed a relatively high self-absorption and CFs values because of the chemical composition changeable between the spiked and unspiked samples. For that, it is better to adopt other methods less expensive, give results faster, higher accuracy and do not make change in the chemical composition. The results were also showed the density factor is the most influential factor in self-absorption phenomena.
\end{abstract}

\section{Introduction}

Lead-210 $\left({ }^{210} \mathrm{~Pb}\right)$ is the most important isotope among the different isotopes of lead, as it is one of its radioactive isotopes and has a long half-life (22.3 years), so it is used to date sediments for the past hundred years, and this has made it extremely important in many different environmental studies [7]. The origin of ${ }^{210} \mathrm{~Pb}$ from the ground, as it results from the ${ }^{238} \mathrm{U}$ chain decay, and is the ninth daughter number in the decay series. We can also consider it as a direct daughter of the radon gas $\left({ }^{222} \mathrm{Rn}\right)$ because of its other daughters' short half-life, which is very short when compared with the half-life of ${ }^{210} \mathrm{~Pb}$.

Due to the importance of ${ }^{210} \mathrm{~Pb}$, there have been numerous studies since the seventies, concern to determine $\left({ }^{210} \mathrm{~Pb}\right)$ in different environmental samples (sediment, soil, plant ...). Alpha spectroscopy was used as a basic method in determining ${ }^{210} \mathrm{~Pb}$ as indirectly method through polonium $210\left({ }^{210} \mathrm{Po}\right)$ [7]. Also, beta spectroscopy was used to identify $210 \mathrm{~Pb}$ through its daughter bismuth $210\left({ }^{210} \mathrm{Bi}\right)$ [7]. Recently, a liquid scintillation counter (LSC) was used [7].

In the twentieth century, gamma spectroscopy was commonly used to determine the ${ }^{210} \mathrm{~Pb}$ directly from gamma energy line that it emits at an energy of $46.5 \mathrm{keV}$ using germanium HPGe semiconductor detectors. This method gives a quick result in comparison with previous methods. It is also the lowest cost, and does not damage the sample and it does not require a chemical preparation of the sample [6].

As a result of the low energy emission of ${ }^{210} \mathrm{~Pb}$ $(46.5 \mathrm{keV})$, an attenuation of the emitted photons is happened within the sample itself which is called SelfAttenuation or Self-Absorption [6]. Self-absorption is affecting the accuracy of the measurement values, and this phenomenon has led to the emergence of many studies that adopt experimental and theoretical methods for determining Self-absorption correction factors for the purpose of improving measurement accuracy, and finding curves (density - correction factor) that are laboratory

\footnotetext{
Corresponding author: jaltuweity2020@gmail.com
} 
approved for each type of environmental sample separately to make automatic and fast corrections [6].

\subsection{Lead-210 applications}

${ }^{210} \mathrm{~Pb}$ is the most important radioisotope in environmental studies. It is widely used in studies of precipitation, sediment history, and geological historical periods that are less than 100 years old. It is also used to measure sedimentation rates in lakes, waterfalls and marine coasts. Goldberg considered it a geological measure of the age of the Earth [10]. It is also used as a tracer for the movement of pollutants in water and air currents and in soil erosion studies.

Determination of ${ }^{210} \mathrm{~Pb}$ activity in air and surface soils gives quantitative information about the flow of ${ }^{222} \mathrm{Rn}$ gas and its daughters into the atmosphere. Since $210 \mathrm{~Pb}$ belongs to the ${ }^{238} \mathrm{U}$ decay chain, it assists in the detection and exploration of it through radon and monitoring the transfer of nuclides in the uranium chain from soil to hydro systems. Additionally, it is used for sediment dating [10] [11]. The importance of dating by radioisotopes is due to their high accuracy, as their uncertainty is very small when compared to the tree rings or icebergs methods. More than forty different isotope dating techniques are now known, and each one depends on a different isotope [8].

Among its applications is the possibility of evaluating the average annual dose of radon, by obtaining the probability of radon escaping from sediments by calculating the ratio of lead activity to radium activity [10].

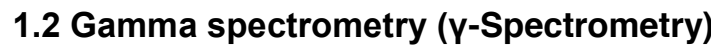

Gamma spectroscopy is the most important method for environmental radiation measurements. It is usually used in radiological monitoring of the environment, and it is suitable for analyzing different types of environmental samples such as sediments, soil, rocks, coal, plants and even liquid samples, after appropriate preparation for each type of these samples.

Determination of ${ }^{210} \mathrm{~Pb}$ is carried out by counting gamma photons from $46.5 \mathrm{keV}$ energy line using N-Type HPGe detector supported with Beryllium or Carbon window. This method is characterized by the speed of its analyzing, as it does not require any chemical separation processes as in the previous methods, and therefore does not destroy the sample, but it requires a large amount of sample. The decrease in the absolute intensity of the $46.5 \mathrm{KeV}$ gamma photons, with $4.26 \%$ probability emission leads to a relative decrease in the counting efficiency of the HPGe detector, in addition to the high self-absorption coefficient of gamma rays in the sample [7] [5].

The HPGe-Detector system was used to identify the low-energy gamma emitters (Be-Window), with Interwinner analyzing software program for radiation analysis of the study samples which is available in the laboratories of the Protection and Safety Department Syrian Atomic Energy Commission - Syria.

\subsection{Self-Absorption}

Self-absorption is the most important factor affecting the accuracy of gamma spectroscopy measurement of environmental samples [4]. We cannot determine the radioactivity of environmental samples by gamma emission without talking about self-absorption calculations [9]. The counting efficiency is affected significantly, especially at low energies less than $100 \mathrm{keV}$. Self-absorption means the absorption of gamma radiation by the sample that emits this radiation, and does not reach the detector.

Self-absorption is affected by many factors' chemical composition of the sample, its geometric shape, thickness, [3], its density, the atomic number, the distance between the sample and the detector, the energy of the emitted gamma photons in addition to other factors such as the coefficient or percentage of humidity in the sample.

Self-absorption coefficient is also defined as the ratio of the number of emitting particles or photons from the source to the number of real particles emitted from it, and in this case its value will be limited between zero and one [1].

We note that the term self-absorption is mentioned in Arabic or English references in the sense synonymous with the term self-attenuation, as it expresses the same physical state that self-absorption is expressed and is calculated by methods and mathematical equations with which it is calculated.

\section{MATERIALS AND METHOD}

\subsection{Soil and sediment: samples collecting and pre-preparation}

Various samples of soil ( $A$ to $E$ ) and sediments (SE1 to $S E 7$ ), about 4 to $5 \mathrm{~kg}$ (kilogram), were collected from different regions in the Syrian Arab Republic. There are many steps to prepare the samples for measuring by gamma Spectroscopy. First step, removing gravel and plants from soil and sediment samples, thin dried them at $95^{\circ} \mathrm{C}$, after that ground with mortar and then passed them through a mesh with holes equal to $1.7 \mathrm{~mm}$ holes for soils samples and $850 \mu \mathrm{m}$ for sediments samples. Each sample was homogenized separately in the homogenizer for a period of at least three hours. In the end of this step we complete the pre-preparation of the study samples.

\subsection{Preparing QCYB40 standard solution}

Steps to prepare the liquid standard reference sample 1 - $5 \mathrm{~mL}$ of QCYB40 standard solution $\left({ }^{210} \mathrm{~Pb}+\right.$ methanol $)$ was added in a cylindrical package and placed in a drying oven to evaporate the methanol.

2- $0.5 \mathrm{~mol}$ of nitrogenous acid was prepared $(3.15 \%$ nitrogenous acid and the rest water)

$3-{ }^{210} \mathrm{~Pb}$ precipitate was mixed in the cylindrical container with $75 \mathrm{~mL}$ of acid prepared in step 2 .

4- Leave the mixture to combine while avoiding shaking the package.

5- The sample was analyzed with gamma spectroscopy. 


\subsection{Preparing the studied samples and labeling them with QCYB40 standard solution}

After their initial preparation, soil and sediment samples were taken, and they were filled on two replicates in identical cylindrical containers of $75 \mathrm{~mL}$. One of the replicators was spike and the other unspike from each sample separately. The spiked samples were placed in a drying oven for approximately 24 hours at a temperature of $75^{\circ} \mathrm{C}$. After that all the spiked and unspiked samples were analyzed using a HpGe Spectroscopy.

\subsection{Gamma Spectroscopy analyzing and mathematic formula}

This method is based on measuring the radioactivity of the studied sample twice, first to determine the natural radioactivity of the sample and the second to determine the radioactivity of the sample after adding a known amount of the standard solution QCYB40 to it which will call spiked sample. QCYB40 is contains the isotope ${ }^{210} \mathrm{~Pb}$, so that we get the same sample but with a higher concentration of the ${ }^{210} \mathrm{~Pb}$ isotope whose activity is known. The spectrums for both of them were collected for every sample separately. The ratio between the spike sample radioactivity to the measured sample, we obtain the self-absorption correction factor of the sample according to the mathematical formula (1). It is also possible to calculate the self-absorption correction factors by calculation of the ratio of the count rate of the water sample to the count rate of the studied sample spiked with the same quantity of $5 \mathrm{~mL}$ standard solution, after subtracting the count rate of the studied sample before spike it from the count rate of the studied sample after spike it. Table (1) shows the results of calculated by counting ratios for the reference sample and the studied sample.

Table 1. Self-absorption factors and CFs for sediment and soil samples.

\begin{tabular}{|c|c|c|c|}
\hline Sample N. & $\begin{array}{c}\text { Density } \\
g / \mathrm{cm}^{3}\end{array}$ & $\begin{array}{c}\text { Self- } \\
\text { absorption } \\
\text { Factor }\end{array}$ & CF \% \\
\hline SE1 & 1.85 & 2.13 & 53 \\
\hline SE2 & 1.57 & 1.58 & 37 \\
\hline SE3 & 1.52 & 2.18 & 54 \\
\hline SE4 & 1.51 & 1.56 & 36 \\
\hline SE5 & 1.44 & 1.63 & 39 \\
\hline SE6 & 1.41 & 1.41 & 29 \\
\hline SE7 & 1.32 & 1.62 & 38 \\
\hline A & 1.68 & 2.25 & 56 \\
\hline B & 1.65 & 2.13 & 53 \\
\hline C & 1.59 & 1.74 & 43 \\
\hline D & 1.52 & 1.68 & 40 \\
\hline E & 1.50 & 1.62 & 38 \\
\hline
\end{tabular}

where activity

$$
\text { correction factor } C F=\frac{\text { Activity(spiked })}{\text { Activity }(\text { sample })}
$$

$$
A_{\frac{B q}{K g}}=\frac{N_{\frac{C}{S}}}{\varepsilon * I_{\gamma} * m_{K g}}
$$

Considering the $I_{\gamma}$ gamma emission probability of ${ }^{210} \mathrm{~Pb}$ with an uncertainty of \pm 0.00009 .

$\varepsilon$ : represents the counting efficiency of the detector.

$m \mathrm{~kg}$ : represents the weight of the studied sample in in grams (g) or kg.

$N_{C S}$ : represents the count rate of the studied or reference sample in cps (several per second)

\section{Results and Discussion}

From Table 1, sediment and soils samples density were between 1.85 to $1.32 \mathrm{~g} / \mathrm{cm} 3$ and 1.68 to $1.50 \mathrm{~g} / \mathrm{cm} 3$ respectively. Also, self-absorption factors were between 1.41 to 2.18 for sediments samples while in soil samples they were 1.62 to 2.25 . The correlation coefficients between self-absorption factor and density were association and very strong in linear curve Fig.2 of the soil samples $\left(\mathrm{R}^{2}=0.92\right)$. In opposite for linear curve of the sediment's samples Fig.1, the correlation coefficients were association but weak $\left(\mathrm{R}^{2}=0.39\right)$. CFs have increased too for sediment samples ranged from $29 \%$ to $54 \%$, and soil samples recorded higher correction than sediments, they were between $38 \%$ to $56 \%$. This is due to the difference in the particle-size of sediment samples, and this leads to a difference in density determination and homogeneity of the samples especially during mixing with the standard solution QCYB40 and this is what the soil samples differ as they appeared more homogeneous in their particle-sizes.

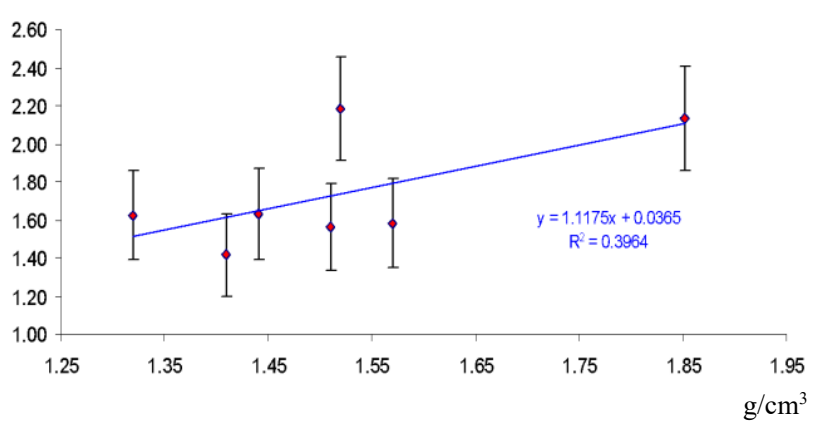

Fig. 1. Show linear curve and correlation coefficients between self-absorption Factor and density of sediment samples-Table1

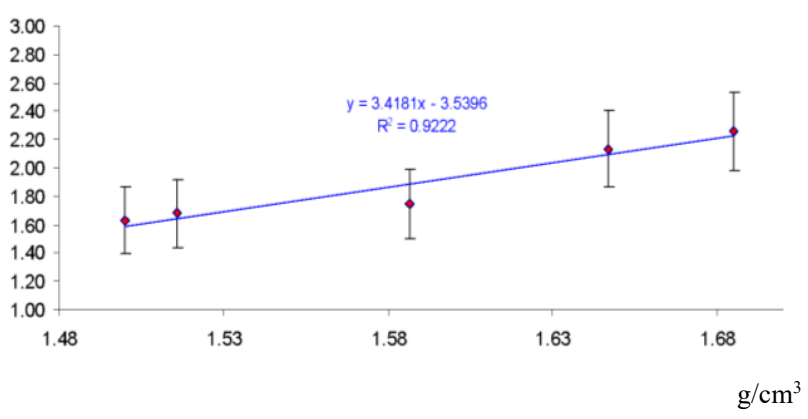

Fig. 2. Show linear curve and correlation coefficients between self-absorption Factor and density of soil samples-Table 1 
Adding a chemical material to the samples is affected within sample chemical composition, density and to the self-absorption factors. For that this method not practical at all with plants samples because it is consisting of organic materials which interact with standard solution.

\section{Conclusion}

The self-absorption correction factors for lead-210 energy $46.5 \mathrm{keV}$ were determined using the spike method for five soil and seven sediment samples which collected from various places in Syrian Arab Republic. Low Energy Spectroscopy HpGe at the laboratories of the Protection and Safety Department - Syrian Atomic Energy Commission - Syria was used. The results showed increasing in the correction factors of the sediment and soil samples. These differences cause of the sample's variation in the chemical composition and density. It is showed density factor is the most influential factor in this method. Also, spike method seems as a complicated and unpractical way, it is a method that affects chemical composition of the samples. So, it is better to adopt other methods that are keep the samples without any chemical composition changeable, less expensive and give faster results with higher accuracy of measurement.

Acknowledgements. The authors would like to thank Pr. Ibrahim Othman General Director of Atomic Energy Commission of Syria AECS for his encouragement and support.

\section{References}

1. Ahmed F.M. Ahmed M.A., Concept of Radiation Physics. Physics Department - College of Science King Saud University, Riyadh. Saudi Arabia.

2. Al-Masri M.S., Hasan M., Amin Y., A Comparison of two nuclear analytical techniques for determination of ${ }^{210} \mathrm{~Pb}$-specific activity in solid environmental. Springer-Verlag, 2009.

3. Boshkova T., Effective of bulk sample in "close" measuring gamma-ray spectrometry. Applied Radiation and Isotopes 59, 1-4, 2003.

4. Jodlowski P., Self-absorption correction in gammaray spectrometry of environmental samples-an overview of methods and correction values obtained for the selected geometries. Nukleonika .51 (2), S21S25, 2006.

5. Johansson L.Y., Determination of Pb-210 and Po210 In Aqueous Environmental Samples, 2008.

6. Knoll G.F., Radiation Detection and Measurement, Third ed. NJ: John Wiley \& Sons, New York, 2000.

7. L'Annunziata M.F., Handbook of radioactivity analysis. San Diego, CA:Academic Press, -ISBN: 012-436603-1, 1998.

8. M.S. Al-Masri, H. Rana, History using natural radioisotopes. Syrian Atomic Energy Commission Damascus, 2010.

9. McMahon C.A., Fegan J.. Determination of selfabsorption corrections for gamma analysis of environmental samples: comparing gamma absorption curves and spiked matrix-matched samples. Appl.Radiat. Isot. 60,571-577, 2004.

10. Pilleyre T., Sanzelle S.. Theoretical and Experimental estimation of self-attenuation correction in determination of ${ }^{210} \mathrm{~Pb}$ by $\gamma$ spectrometry with well Ge detector. Radiation Measurements 41,323-329,2006.

11. Pittauerova' D., Application of self-absorption correction method in gamma spectroscopy for $210 \mathrm{~Pb}$ and ${ }^{137} \mathrm{Cs}$ sediment chronology on the continental slope off NW Africa. Radioprotection, 44, 457 - 461, 2009. 